\title{
Cerebral White Matter Injuries Following a Hypoxic/Ischemic Insult During the Perinatal Period: Pathophysiology, Prognostic Factors, and Future Strategy of Treatment Approach. A Minireview
}

\author{
Christian Zammit ${ }^{1}$, Richard Muscat ${ }^{2}$, Gabriele Sani ${ }^{3}$, Cristoforo Pomara ${ }^{1,4, *}$ and Mario Valentino ${ }^{2}$ \\ ${ }^{I}$ Department of Anatomy, Faculty of Medicine and Surgery, University of Malta; ${ }^{2}$ Department of Physiology and Bio- \\ chemistry, Faculty of Medicine and Surgery, University of Malta; ${ }^{3}$ NESMOS Department, Sapienza University, Rome; \\ Psychiatric Unit, Sant'Andrea Hospital, Rome; Centro Lucio Bini, Rome; ${ }^{4}$ Department of Forensic Medicine, Univer- \\ sity of Foggia
}

\begin{abstract}
Recent advances in medical care have significantly improved the survival rate of neonates who suffer a hypoxic/ischemic event, before, during, or after birth. These infants are extremely vulnerable to brain injury and are at high risk of developing motor and cognitive abnormalities later on in life. The regional distribution of perinatal brain injury varies, and depends primarily on; the severity, pattern and type of insult, the metabolic status, and on the gestational age. The principal neuropathological substrate that is affected in the premature infant is cerebral white matter. The aim of this article is to reexamine the current knowledge on the ischemic pathophysiology of all cellular components that comprise the white matter, predict the consequences of the long-term neurological outcome, and analyze possible therapeutic strategies. Although oligodendrocytes have long been regarded as the hallmark of perinatal white matter injury, axons, astrocytes and microglia, all contribute to the complex pattern of brain injury that occurs in this cohort of individuals. It is hoped that a better understanding of the pathophysiology of white matter injury and its underlying prognostic factors, may lead to the development of new therapeutic strategies for such a complex and debilitating condition.
\end{abstract}

Keywords: Perinatal ischaemia, periventricular leukomalacia, cellular mechanism, cerebral palsy, prognostic factors, treatment approach.

\section{INTRODUCTION}

Ischemic injury of preterm infants must be considered a major issue in today's society. The incidence of perinatal stroke has been estimated at one in 1600 to 5000 births worldwide [1-3], but its occurrence is probably underestimated due to the variability in clinical and diagnostic criteria. Infection/inflammation and ischemia/reperfusion injuries are the two main mechanisms in the pathogenesis of Periventricular Leukomalacia (PVL) [4]. There are a number of well established risk factors that predispose to perinatal brain injury. According to a recent classification, such factors can be divided into: maternal disorders (infertility, pre-eclampsia, chorioamnionitis, substance abuse), placental disorders (placental thrombosis, abruption, infection), blood disorders (polycythemia, disseminated intravascular coagulopathy, Protein S and C deficiency, antiphospholipid antibodies), homocysteine and lipid disorders, cardiac disorders (congenital heart disease, patent ductus arteriosus, pulmonary valve atresia, cardiac surgery), infectious disorders (meningitis, systemic infection), and other miscellaneous disorders (vascular maldevelopment, arterial dissection, trauma, dehydration, catheterisation) [5]. Major advances in medical treatment have led to the survival of almost $90 \%$ of low birth weight infants [6] but about $10 \%$ of them later develop spastic motor deficits [79], and about $20-25 \%$ later exhibit cognitive, attentional, behavioural, and/or socialisation defects that significantly impair their quality of life [10-12]. PVL is the most common cause of brain injury in premature infants [13] and results from a hypoxic/ ischemic insult during the high-risk developmental period of 23 to 32 weeks of gestation [14], and to a lesser extent, as a result of germinal matrix intraventricular haemorrhage with asymmetric necrosis of the periventricular white matter [15]. The pathogenesis of PVL comprises systemic infection and inflammation, and

*Address correspondence to this author at the Department of Anatomy, Faculty of Medicine and Surgery, University of Malta;

Tel: 0035623402795; Fax: 0035621319527;

E-mail: cristoforopomara@hotmail.com maturation-dependent intrinsic vulnerability of premyelinating oligodendrocytes [16]. However, white matter damage in PVL is not restricted to oligodendrocytes. Dammam et al. [17] suggested that white matter damage due to PVL involves deficits in oligodendroglia, loss of axonal fibres, microgliosis, and astriogliosis (Fig. 1).

\section{OLIGODENDROCYTE INJURY}

Oligodendrocyte injury has long been regarded as the hallmark of PVL. Oligodendrocyte development occurs in four stages: early oligodendrocyte progenitor cell (OPC), late OPC (also called premyelinating oligodendrocytes), immature myelinating oligodendrocyte, and mature myelinating oligodendrocyte [18]. Back et al. [19] reported that late OPC are significantly more vulnerable to ischemia than early OPC. This maturation-sensitivity of the late OPC leads to preferential white matter injury in the neonate [16] and coincides with the high-risk period for PVL in humans [20]. Injury of the late $\mathrm{OPC}$ is therefore regarded as the main pathological lesion seen in cerebral white matter in the neonate [21]. The major factors that underlie the maturation-dependent susceptibility of the late OPCs are: (i) abundant production of reactive oxygen and nitrogen species in combination with delayed development of glutathione antioxidant defences, (ii) acquisition of $\mathrm{Fe}^{2+}$, and (iii) exuberant expression of the major glutamate receptors (GluRs) ( $\alpha$-amino-3-hydroxy-5methyl-4-isoxazolepropionic acid (AMPA) receptors deficient in the GluR2 subunit and of N-methyl-D-aspartate (NMDA) receptors (both $\mathrm{Ca}^{2+}$-permeable)) [16].

Although the vulnerability of the late OPC is one of the hallmarks of the increased susceptibility of white matter injury to ischemia during development, as we previously reported, the immature myelinating oligodendrocytes also contribute to the continuum of white matter vulnerability following ischemia [22, 23]. Thirty minutes of oxygen-glucose deprivation (OGD) is sufficient to kill almost $70 \%$ of oligodendrocytes, and the percentage of dead oligodendrocytes in neonatal mice (P10 - post-natal day 10) is significantly higher than that in older age groups (Fig. 2). Since in the mouse optic nerve immature myelinating oligodendrocytes 


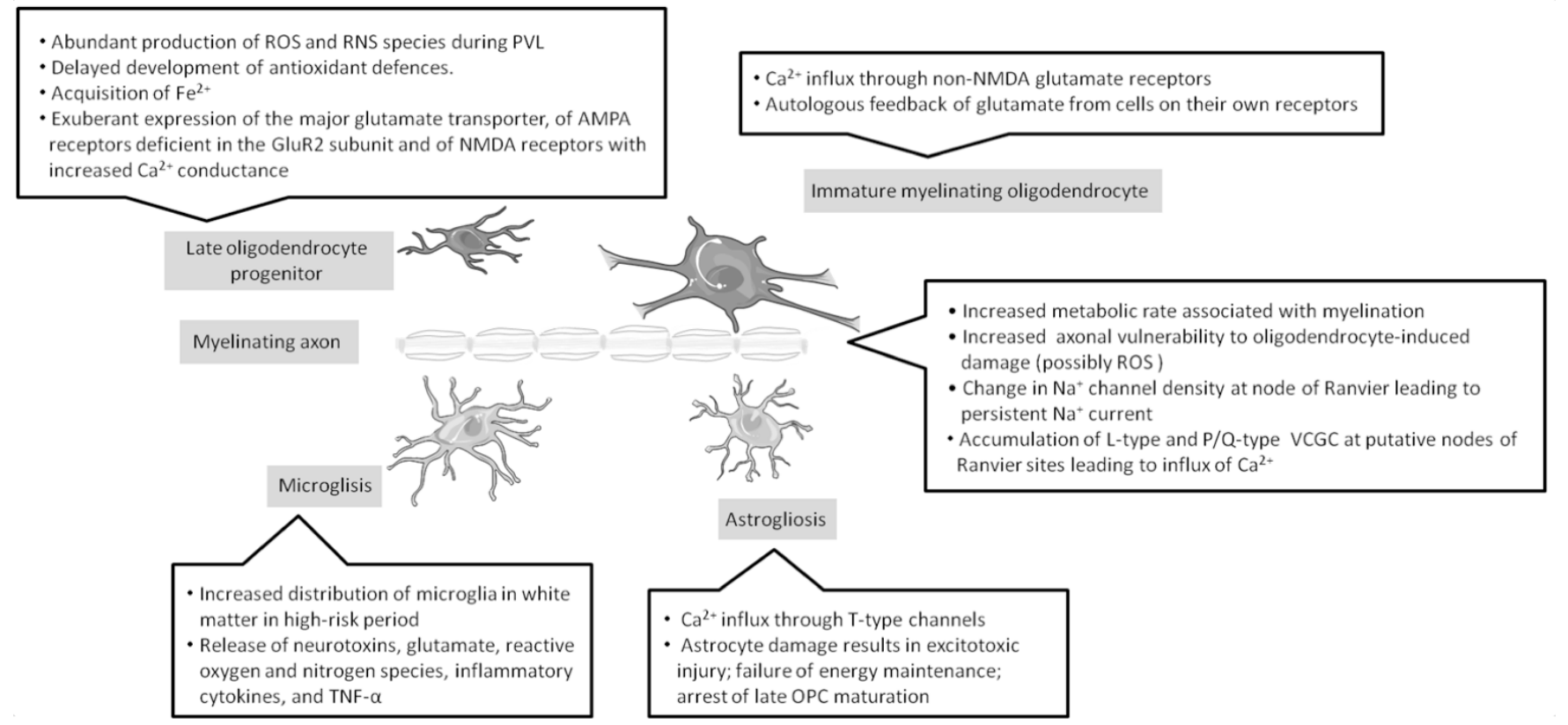

Fig. (1). Cellular mechanisms of injury in perinatal white matter ischemia.

Cartoon depicts the stage-specific mechanisms that are thought to contribute to the heightened sensitivity of all components of white matter injury during the perinatal period.
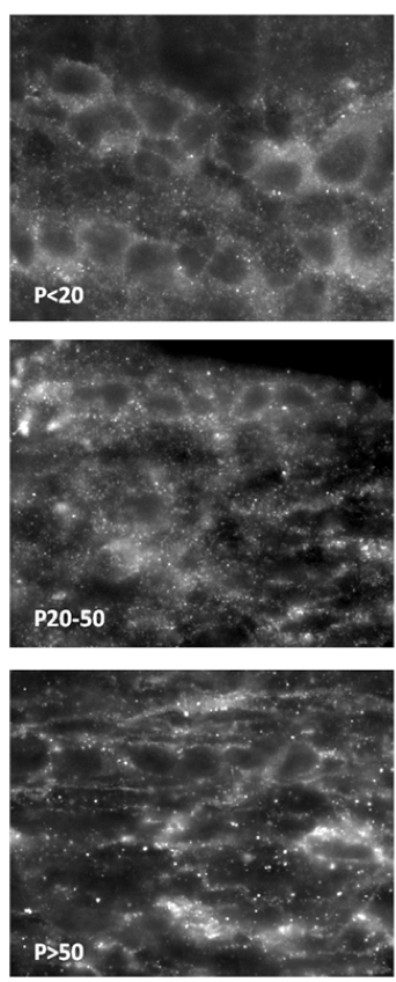
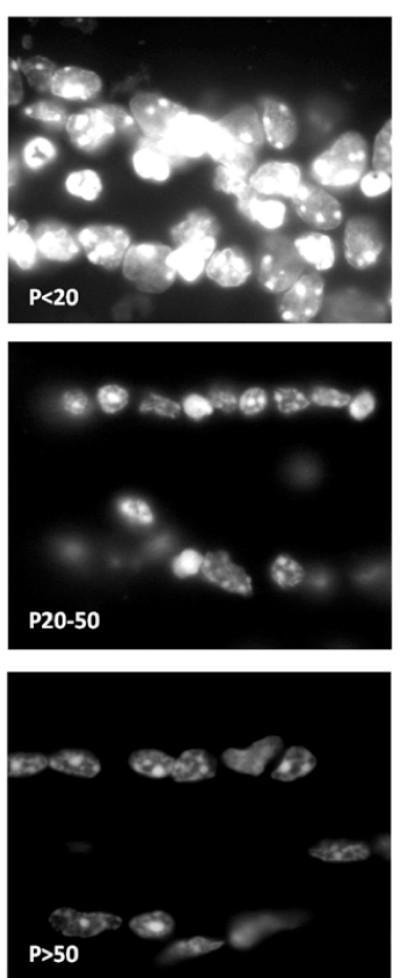

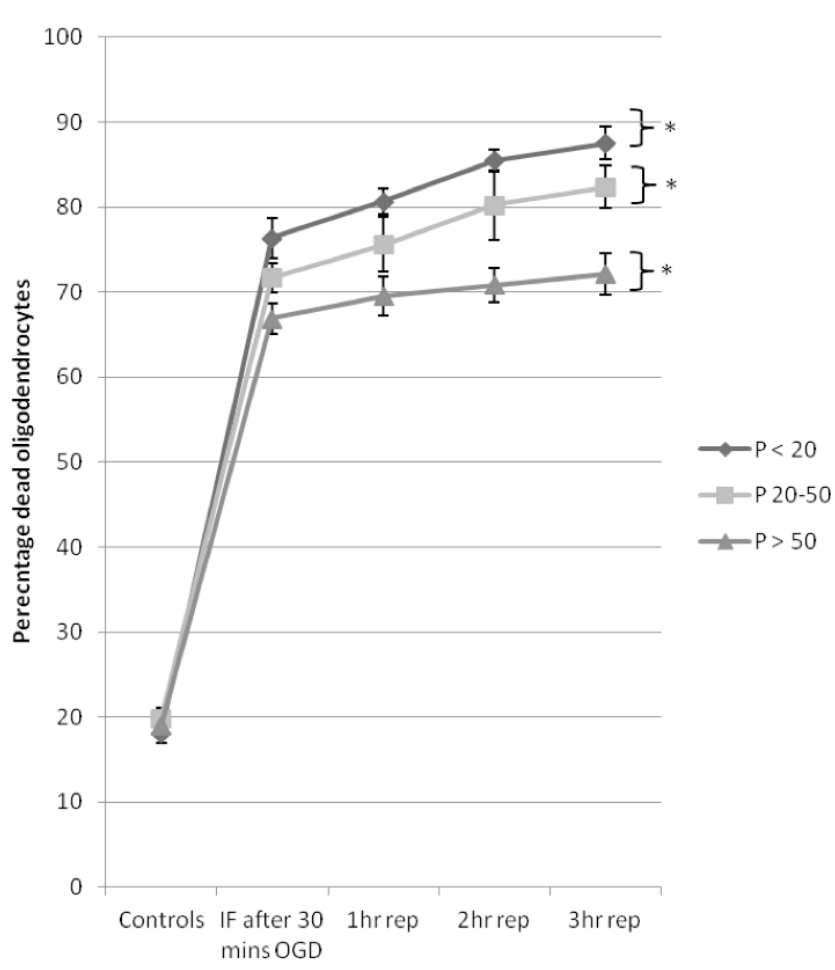

Fig. (2). Heightened vulnerability of immature myelinating oligodendrocytes to ischaemia.

Left: Cropped sections from high power micrographs (X60) of optic nerve sections from 3 different age groups $(\mathrm{P}<20, \mathrm{P} 20-50$, and $\mathrm{P}>50)$ immunostained with anti-APC (left) and Hoechst stain (right) after 60 mins OGD. Optic nerves from $\mathrm{P}<20$ mice had a greater number of pyknotic nuclei when compared to older age groups. Right: Comparison of the percentage of dead oligodendrocytes following ischemia between different age groups. There was a statistically significant difference $(* p \leq 0.05)$ in the percentage of dead oligodendrocytes between the different age groups after 30 mins of OGD. APC $+v e$ oligodendrocytes at $P$ $<20$ were the most vulnerable to injury. (OGD - Oxygen-glucose deprivation; IF - immediately fixed ; $1 \mathrm{hr}-1$ hour reperfusion; $2 \mathrm{hr}-2 \mathrm{hours}$ reperfusion; $3 \mathrm{hr}$ -3 hours reperfusion). 
predominate at around $\mathrm{P} 7$ to $\mathrm{P} 10$ [20], our results suggest that immature myelinating oligodendrocytes are more vulnerable than mature myelinating oligodendrocytes. In cell cultures, mature oligodendrocytes (A2B5- $/ \mathrm{GC}^{+}$) are more resistant to ischemia than immature ones (O4+/GC-) [24]. Results from these studies suggest that rapid ischemic cell death of immature oligodendrocytes is mediated by $\mathrm{Ca}^{2+}$ influx via non-NMDA glutamate receptors, and exacerbated by significant autologous feedback of glutamate from cells on their own receptors [24].

\section{LOSS OF AXONAL FIBRES}

The sensitivity of rat grey matter to anoxia and aglycaemia increases progressively from birth to adulthood; consistent with the rise in metabolic demand of this tissue $[25,26]$. However, white matter does not follow a similar pattern. After a period of increased tolerance to ischemia (P3 mice), Fern et al. [27] reported an increased vulnerability to ischemia of white matter in terms of functional loss of conduction in P20-P50 mice. This vulnerability starts to decrease at P50, which is in agreement with our published observations [22], wherein the degree of ischemia-induced structural axonal injury in P20 - P50 mice is significantly higher than in any other age group (Fig. 3).

In the mouse optic nerve, myelination starts at around P7, with few axons having only one whorl of myelin at this age [28]. The rate of myelin deposition thereafter peaks at P21-P28, and from this point onward, the process of myelination is at its highest [29]. The period of low tolerance to ischemia observed [22] in mice between P20 and P50 coincides with this process of myelination, and the increase in sensitivity to ischemia can be attributed to the onset of the associated heightened metabolic activity [30-32]. Fowler et al. [33] proposed that myelination might increase axonal vulnerability to oligodendrocyte-induced damage, since perturbation of the oligodendrocyte-myelin-axon interaction in myelinated white matter decreased axonal damage after AMPA administration in rats. Myelination is not the only contributor to this increased vulnerability, as $\mathrm{Na}^{+}$-channel density in optic nerve axons also varies with age. This starts from $<2 / \mu \mathrm{m}^{2}$ in the neonate [34], increasing up to the age of about P25, and declining during adulthood [35]. During myelination $\mathrm{Na}^{+}$channels aggregate at the nodes of Ranvier, and ischemia causes an increase in density and a persistent non-inactivating $\mathrm{Na}^{+}$ current that leads to increased axonal calcium flux through reversal of the $\mathrm{Na}^{+} / \mathrm{Ca}^{+}$exchanger [36].

As we previously reported [23], large ( $>0.4 \mu \mathrm{m}$ in diameter) pre-myelinating axons are more sensitive to OGD than smaller premyelinated and myelinating axons. Blockade of NMDA and nonNMDA GluRs alone provides only partial protection from ischemic injury whereas addition of L-type and P/Q-type voltage-gated calcium channel (VGCC) blockers to these GluRs antagonists results in complete recovery of the compound action potential [23, 37]. Comparison of OGD-induced damage to small $(<0.4 \mu \mathrm{m})$ and to large $(>0.4 \mu \mathrm{m})$ premyelinating axons shows that the former are protected by GluR blockers alone, whilst the latter needs addition of VGCC-blockers to confer protection [23]. This study shed light on the importance of VGCC in this age group, and on the pathophysiological mechanism of injury during ischemia in these very sensitive axons.

\section{MICROGLIOSIS}

Numerous studies have demonstrated that activated microglia trigger injury to immature white matter causing injury to surrounding neurons and glia through the release of neurotoxins, glutamate, reactive oxygen species, nitric oxide and inflammatory cytokines [38-40]. Other substances released from microglia, such as tumour necrosis factor- $\alpha(\mathrm{TNF}-\alpha)$, can increase the susceptibility of surrounding neurons and oligodendrocytes to ischemic injury [41]. It was also demonstrated that lipopolysaccharide-activated microglia
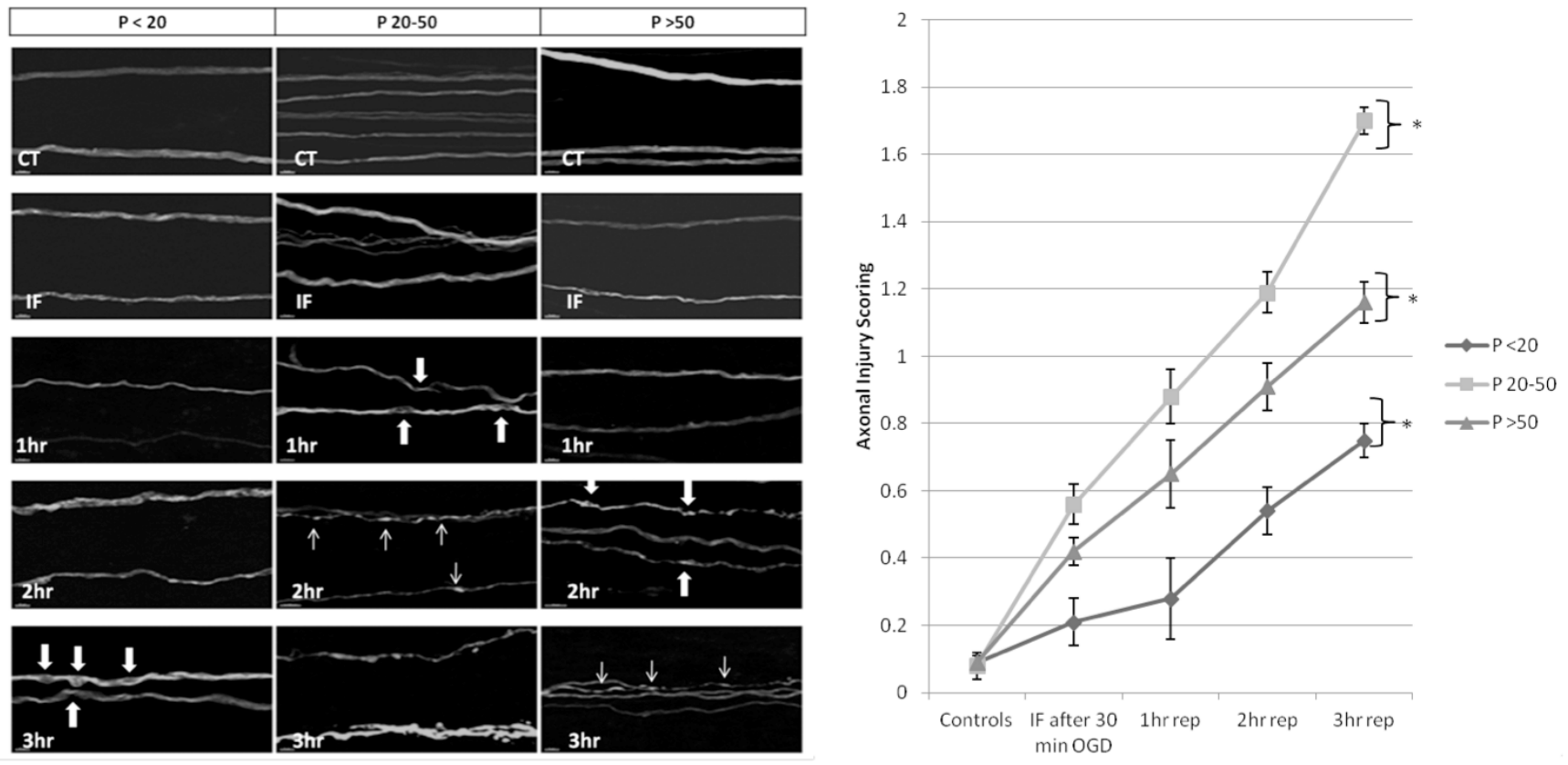

Fig. (3). Heightened vulnerability of actively myelinating axons to ischaemia.

Left: Confocal images (Magnification X 60 lens - X 400 digital zoom) of Thy-1/GFP-M mice from 3 different age groups following 30 mins OGD. There is progression of injury in all age groups, but features of axonal damage were first evident in P20-50 mice, followed by $\mathrm{P}>50$ mice, and finally $\mathrm{P}<20$ mice. Thick arrows mark axonal swelling; thin arrows mark beading and fragmentation. Right: Comparison of axonal injury following ischemia between different age groups. There was a statistically significant difference $(* p \leq 0.001)$ in axonal injury score between the different age groups at each time point following 30 mins of OGD. P20-50 mice (box) were the most vulnerable to injury, and P $<20$ mice (diamond) were the most resistant. (OGD - Oxygen-glucose deprivation; $\mathrm{IF}$ - immediately fixed ; $1 \mathrm{hr}-1$ hour reperfusion; $2 \mathrm{hr}-2$ hours reperfusion; $3 \mathrm{hr}-3$ hours reperfusion). 
adversely affected the survival and development of oligodendrocyte progenitor cells, reducing the production of myelin basic protein [42]. Therefore, disturbance of myelination in PVL is believed to be due to arrested maturation of premyelinating oligodendrocytes induced by nitrosative and oxidative mechanisms mediated by microglial cells $[43,44]$.

The density of microglia in the brain varies throughout development [45]. During the period of high sensitivity of the human brain to ischemia, activated microglia are concentrated in the cerebral white matter. This maturation-dependent distribution of microglia might also play a role in the selective white matter injury during this stage, since microgliosis is a prominent feature of cerebral white matter injury seen in premature infants [45].

\section{ASTRIOGLIOSIS}

Astrocytes play a vital role in the normal physiology of the human brain. They regulate synaptogenesis, neurotransmission, metabolic support, blood-brain barrier formation/maintenance, and actively participate in the innate immune response [46-48]. Therefore, they are likely to be involved in the cascade of pathological events that occur in the immature brain in response to infection and/or inflammation [46]. Neonatal white matter astrocytes are highly susceptible to ischemic injury $[49,50]$. This high sensitivity is due to an exaggerated $\mathrm{Ca}^{2+}$ influx through T-type VGCC [51]. Damage to astrocytes causes impairment of astrocyte glutamate receptors resulting in the excessive accumulation of extracellular glutamate that contributes to the excitotoxic injury of oligodendrocytes and axons [52]. It also disrupts the homeostatic and metabolic regulation of glucose and lactate, with subsequent failure of energy maintenance [53]. Moreover, inhibitory factors released from reactive astrocytes arrest the maturation of late OPCs [54].

\section{PREDICTORS OF LONG-TERM NEURODEVELOPMEN- TAL OUTCOME FOLLOWING NEONATAL ISCHEMIA}

In the developing immature brain, ischemic brain injury predisposes to cerebral palsy, a non-progressive motor disorder of movement and posture, which is often accompanied by disturbances in sensation, perception, cognition, communication and behaviour [55]. Improved neonatal care within the last decade has lead to the increased survival of preterm and low-birth-weight infants. However, this resulted in an increased risk of adverse long-term outcomes, especially with respect to cognitive and behavioural deficits [56].

The age and location of the insult are important determinants and predictors of neurodevelopmental outcome. There is considerable evidence that an early brain insult is associated with a broad spectrum of neuropsychological dysfunction $[57,58]$. In fact, the onset of stroke at a younger age predisposes to an overall worse prognosis [59-61], weaker cognitive performance, and is subject to lesion location [62]. Westmacott et al. [62] reported that individuals who suffered a subcortical stroke (affecting the thalamus and/or basal ganglia axis) before the age of 28 days performed significantly poorer in terms of intellectual performance than older children with the same insult. In contrast, in the case of cortical strokes, the period of greatest vulnerability appears to be within 1 month and 5 years. In a more recent study, Studer et al. [63] found that cognitive outcome in children who suffered an acute ischemic stroke (defined as focal neurological deficit of acute onset confirmed by cranial Computed Tomography (CT) or Magnetic Resonance Imaging (MRI) showing an infarction in a corresponding location) between 1 month and 3 years was worse than in older children. However they did not find any influence of lesion location (cortical or subcortical) to the overall outcome. They hypothesized that rather than lesion location, lesion size is a more valid predictor of overall outcome, since larger lesions disrupt a wider network of neural connections, resulting in worse cognitive outcomes. Maitre et al. [64] reported a similar finding; infants who suffered unilateral periventricular hemorrhagic infarction had better motor and cognitive outcomes than infants with bilateral periventricular hemorrhagic infarction.

Preterm born very-low-birth-weight (VLBW: birth weight $<1500 \mathrm{~g}$ ) infants are at an increased risk to develop perinatal brain injuries that will ultimately result in abnormal brain development $[4,9]$. Several studies have investigated the relationship between perinatal brain injuries in VLBW survivors and brain development [65-67]. In a recent meta-analysis, de Kieviet et al. [68] summarised that VLBW infants who suffer perinatal brain injury develop smaller total brain volume with reduced volume of grey and white matter. Such injuries may influence cognitive development and performance [21, 68]. Aarnoudse-Moens et al. [69] reported a reduction in academic achievements and problems with behaviour, attention and executive functions in VLBW children that are correlated to the degree of immaturity at birth. A recent study by Bjuland et al. [70] investigated the difference in brain volumes and cognitive abilities between VLBW subjects and term born controls. They reported a reduction in absolute volumes of several brain structures (mainly thalamus, caudate nucleus, cerebellar white matter and corpus callosum) with the most immature and smallest VLBW birth infants having the most pronounced volume reduction. This decrease in brain volume was also correlated with a reduction in IQ levels, which suggested that perinatal brain injury associated with VLBW induces permanent deficits in cognitive abilities later on in life. Taylor et al. [71] also reported a significant correlation between IQ levels and cerebral white matter volume in VLBW adolescents.

Jakobson et al. [72] suggested that deficits in mental capabilities related to premature births are not due to prematurity per se, but from complications associated with it. This was further validated by Pavlova et al. [73], who reported no difference in mental calculation scores between term-born and premature-born babies with normal MRI findings. However, pre-term infants are prone to various complications, including late-onset sepsis [74]. This leads to white matter abnormalities later on life [75-77], since the preterm brain, in particular white matter, is highly vulnerable to damage by inflammation and ischemia [78]. van der Ree et al. [79] investigated the effect of late-onset sepsis in preterm children. The majority of preterm infants who survived the late onset sepsis showed a lower intelligence, impaired attention and verbal memory, and an abnormal motor outcome at school age (6 to 9 years). Moreover, multiple episodes of sepsis result in a worse outcome, possibly due to progressive white matter injury following recurrent infections [80].

Biomarkers have become increasingly utilised as non-invasive tools in the early diagnosis of various clinical conditions. Recently, Andrikopoulou et al. [81] reviewed some markers that can be used as early detectors of perinatal ischemia; indicators that may help in predicting the prognosis of such infants. Detection of nucleated red blood cells at birth reflects a response of the infant to perinatal hypoxia [82] and can be used for the assessment of the severity and early outcome after perinatal asphyxia [83]. Glial fibrillary acidic protein (GFAP) is a brain-specific cytoskeletal intermediate filament protein found in astrocytes. Studies have explored the use of this marker for the early diagnosis of patients with stroke [84]. Ennen et al. [85] observed significantly elevated GFAP concentrations in blood samples in patients with hypoxic-ischemic encephalopathy when compared with controls. Systemic infection is one of the main contributing factors to cerebral white matter injury [86], and therefore inflammatory cytokines may be useful as markers of the inflammatory response post-injury. Ellison et al. [87] found that preterm infants with MRI-defined cerebral white matter lesions had higher levels of interleukin (IL)-6, IL-10, and TNF- $\alpha$ in their cerebrospinal fluid, than infants without such findings. Ramaswamy et al. [88] reported that serum and cerebrospinal fluid concentrations of IL-1b and IL-6 were predictors of abnormal outcome in 
patients with hypoxic-ischemic injury. S-100 is a calcium binding protein and is a major component of the cytosol in glial cells. Qian et al. [89] reported elevated levels of this protein in neonates with hypoxic-ischemic encephalopathy. Gazzolo et al. [90] demonstrated that a high concentration of S100 had a sensitivity of $91.3 \%$ and a specificity of $94.6 \%$ for predicting the development of hypoxicischemic encephalopathy.

\section{NEUROIMAGING ASSESSMENT OF PVL}

Neuroimaging is a widely used tool to assess the severity of brain injury following foetal or neonatal ischemia, since the longterm outcome in such infants depends on the nature of the initial insult [91]. Cranial ultrasonography (US) is very useful for the detection of intraventricular hemorrhage and cystic PVL. It is readily applied at the bedside, does not involve ionizing radiation, is costeffective, and can be used sequentially [92]. Multiple single, and multi-centre studies reported an association between cranial US findings and adverse neurodevelopmental outcomes [93-95]. The strongest predictors of subsequent cerebral palsy visualised on US are ventriculomegaly and white matter echolucencies [96]. Application of advanced techniques, including the use of high-resolution linear transducers and Doppler assessment of intracranial vasculature, assist in maximizing the value of this important tool [97]. However, cranial US has its limitations. Brain views are limited to what can be seen through the fontanelles [94] and only $30 \%$ of white matter injuries are consistently detected with US. These include areas of necrosis, diffuse gliosis, cystic PVL, and ventriculomegaly due to periventricular white matter loss [98]. Inder et al. [99] reported that $55 \%$ of infants with a normal cranial US showed extensive signal intensity abnormalities or cystic changes in the cerebral white matter on Magnetic Resonance Imaging (MRI).

Multiple studies [100, 101] reported that MRI findings have a higher sensitivity and specificity to predict cerebral palsy when compared to cranial US. Woodward et al. [102] found significant associations between the qualitative measures of cerebral whiteand gray-matter abnormalities on MRI, and the subsequent risks of adverse neurodevelopmental outcomes at two years of age. In addition, moderate to severe white matter abnormalities were predictive of severe psychomotor delay and cerebral palsy. In a recent study, Imamura et al. [103] investigated the relationship between MRI findings and neurodevelopmental outcome of children with PVL. They graded PVL based on MRI findings [104] as Grade 1, 2 and 3. Children with Grade 1 PVL had abnormally high signal intensity in the periventricular white matter on $\mathrm{T} 2$ and fluid-attenuated inversion recovery images, most commonly observed bilaterally in the trigone regions of the lateral ventricles. In Grade 2 PVL there was loss of the periventricular white matter in the regions with abnormally high signal intensities, and ventricular enlargement adjacent to the regions of the lateral ventricles. In Grade $3 \mathrm{PVL}$ there was focal and extensive cystic changes in the white matter. Children with Grade 2 and 3 had severe neurodevelopmental delays with a high degree of motor impairment and cognitive disability. On the other hand, $56 \%$ of infants with Grade 1 PVL had normal psychomotor development [103]

Radiologists routinely read clinical MRIs qualitatively. Although this is a useful technique for clinical decision-making, it does not provide quantitative values that can be used to monitor neurodevelopmental progress. Recent advances in MR imaging modalities provide new tools for researches to assess quantitatively injury to brain structures. MR Diffusion tensor imaging is widely accepted for use in paediatric studies [105]. Using this technique on PVL patients, Wang et al. [106] reported a significant reduction in mean fractional anisotropy (FA) value (sensitive to axon size, density, organisation and degree of myelination) in a number of white matter tracts (corticospinal tract, internal capsule, arcuate fasciculus, posterior thalamic radiation, corona radiate, superior longitudinal fasciculus, and splenium of corpus callosum). These subjects also showed various degree of cognitive and motor impairment. Cognitive functions are supported by a network of multiple interconnected cortical and subcortical regions, and the integrity of the connecting white matter is an essential tool for efficient cognitive processing [107]. Since there is a correlation between the FA value and cognitive function in terms of IQ score [108], Wang et al. [106] demonstrated that the disturbance of the cognitive ability in preterm children with PVL was significantly correlated to the disruption of white matter microstructure in widespread areas of the brain.

\section{CURRENT AND FUTURE THERAPEUTIC APPROACH}

To date, there is no known effective treatment for PVL. Apart from therapeutic hypothermia $[109,110]$, none of the proposed experimentally neuroprotective treatments have managed to find their places in standard clinical practice [111]. However, continuous research is being done to develop new therapeutic regimens to treat or prevent the development of PVL.

Glutamate excitotoxicity is a main factor in the pathophysiology of hypoxia-ischemia in the neonate. Magnesium is an NMDA receptor antagonist, and prevents neuronal influx of $\mathrm{Ca}^{2+}$. The use of magnesium in clinical trials has produced conflicting results. One trial showed some neuroprotective benefit in term infants with severe asphyxia [112]. In another, Rouse et al. [113] reported a non-significant reduction in stillbirth or death in one year, but a statistical significant reduction in moderate to severe cerebral palsy. Anticonvulsant drugs, like memantine and topiramate also reduce glutamate toxicity by blocking NMDA and AMPA receptors respectively. These drugs were found to be highly effective in reducing brain injury following hypoxia/ischemia [114, 115]. Erythropoietin inhibits apoptosis, neuronal excitotoxicity, and inflammation. Infants with neonatal encephalopathy treated with this drug displayed a significant reduction in terms of mortality and disability [116].

Since reactive oxygen species are one of the hallmarks of perinatal ischemic injury, free radical scavengers have also been tested as possible therapeutic strategies. Antenatal administration of allopurinol was found to reduce the degree of hypoxic-ischemic encephalopathy in neonates exposed to foetal hypoxia [117]. Other anti-oxidants such as 2-iminobiotic and indomethacin were also found to be effective [118]. Antioxidant enzymes administrated prophylactically during pregnancy reduced neuronal injury in rat pups subjected to hypoxia-ischemia [119]. Vitamin K has been shown to prevent oxidative injury to undifferentiated oligodendrocytes [120], but to date no clinical trials have been done to evaluate its potential to decrease inflammatory or ischemic injury during perinatal ischemia.

The role of pro-inflammatory cytokines in the pathophysiological cascade leading to neonatal brain damage is increasingly recognized. Postnatal systemic administration of Interleukin-1 receptor antagonist was found to preserve motor function and exploratory behaviour in rats following exposure to inflammation and/or postnatal hypoxia-ischemia [121].

In recent years, stem cell treatment has generated interest in many medical fields, particularly in conditions with irreversible organ damage and non-available specific treatment. Animal studies support the idea that cord blood and mesenchymal stem cells have a therapeutic effect in neonatal hypoxic-ischemic encephalopathy [122]. These effects have been attributed to immunomodulation, activation of endogenous stem cells, release of growth factors, and anti-apoptosis mechanisms [123]. Intranasal administration of mesenchyme stem cells in neonatal mice, reduced the brain lesion volume induced by hypoxia/ischemia and improved their motor and cognitive behaviour [124]. In a currently ongoing Phase I clinical trial, Mancías-Guerra et al. [125] are assessing the safety, tolerability and efficiency of bone marrow-derived total nucleated cells, in patients diagnosed with cerebral palsy. Their preliminary results are 
promising, with good safety results and improvement in neurological function.

\section{CONCLUSION}

Cerebral white matter injury following a hypoxic or ischemic insult during the neonatal period can lead to severe disability later on in life, both in terms of motor disorders and cognitive impairment. The nature of this condition is such that it does not only affect the patients. Its ramifications cause considerable burden upon the people closest to them and to society in general. Better understanding of the pathophysiology of this condition might give new insights in developing new therapeutic modalities for such a challenging disease. Moreover, identifying crucial prognostic factors that determine long-term neurodevelopment outcomes may possibly help identify individuals at risk. Such patients would benefit from proper rehabilitative care and better assistance throughout the early stages of development, thereby ameliorating their quality of life.

\section{CONFLICT OF INTEREST}

The authors confirm that this article content has no conflict of interest.

\section{ACKNOWLEDGEMENTS}

Declared none.

\section{REFERENCES}

[1] Laugesaar R, Kolk A, Tomberg T, et al. Acutely and retrospectively diagnosed perinatal stroke: a population-based study. Stroke 2007; 38(8): 2234-40.

[2] Lee J, Croen LA, Backstrand $\mathrm{KH}$, et al. Maternal and infant characteristics associated with perinatal arterial stroke in the infant. JAMA 2005; 293(6): 723-9.

[3] Schulzke S, Weber P, Luetschg J, Fahnenstich H. Incidence and diagnosis of unilateral arterial cerebral infarction in newborn infants. J Perinat Med 2005; 33(2): 170-5.

[4] Volpe JJ. Neurology of the newborn. 5th ed. Philadelphia: Saunders Elsevier; 2008.

[5] Lynch JK. Epidemiology and classification of perinatal stroke. Semin Fetal Neonatal Med 2009; 14(5): 245-9.

[6] Deng W, Pleasure J, Pleasure D. Progress in periventricular leukomalacia. Arch Neurol 2008; 65(10): 1291-5.

[7] Doyle LW, Roberts G, Anderson PJ; Victorian Infant Collaborative Study Group. Outcomes at age 2 years of infants $<28$ weeks' gestational age born in Victoria in 2005. J Pediatr 2010; 156(1): 49-53.

[8] Beaino G, Khoshnood B, Kaminski M, et al. Predictors of cerebral palsy in very preterm infants: the EPIPAGE prospective population-based cohort study. Dev Med Child Neurol 2010; 52(6): e11925 .

[9] Mercier CE, Dunn MS, Ferrelli KR, Howard DB, Soll RF; Vermont Oxford Network ELBW Infant Follow-Up Study Group. Neurodevelopmental outcome of extremely low birth weight infants from the Vermont Oxford network: 1998-2003. Neonatology 2010; 97(4): 329-38.

[10] Msall ME. Central nervous system connectivity after extreme prematurity: understanding autistic spectrum disorder. J Pediatr 2010 Apr; 156(4): 519-21.

[11] Anderson PJ, De Luca CR, Hutchinson E, et al. Attention problems in a representative sample of extremely preterm/extremely low birth weight children. Dev Neuropsychol 2011; 36(1): 57-73.

[12] Johnson S, Fawke J, Hennessy E, et al. Neurodevelopmental disability through 11 years of age in children born before 26 weeks of gestation. Pediatrics 2009; 124(2): e249-57.

[13] Back SA, Rivkees SA. Emerging concepts in periventricular white matter injury. Semin Perinatol 2004; 28(6): 405-14.

[14] Alix JJ. The pathophysiology of ischaemic injury to developing white matter. Mcgill J Med 2006; 9(2): 134-40.

[15] Horbar, JD. Vermont-Oxford Network 1997 Database Summary. Vermont-Oxford Network, Burlington; 1997

[16] Volpe JJ, Kinney HC, Jensen FE, Rosenberg PA. The developing oligodendrocyte: key cellular target in brain injury in the premature infant. Int J Dev Neurosci 2011; 29(4): 423-40.
[17] Dammann O, Hagberg H, Leviton A. Is periventricular leukomalacia an axonopathy as well as an oligopathy? Pediatr Res 2001; 49(4): 453-7.

[18] Back SA. Perinatal white matter injury: the changing spectrum of pathology and emerging insights into pathogenetic mechanisms. Ment Retard Dev Disabil Res Rev 2006; 12(2): 129-40.

[19] Back SA, Han BH, Luo NL, et al. Selective vulnerability of late oligodendrocyte progenitors to hypoxia-ischemia. J Neurosci 2002; 22(2): 455-63.

[20] Craig A, Ling Luo N, Beardsley DJ, et al. Quantitative analysis of perinatal rodent oligodendrocyte lineage progression and its correlation with human. Exp Neurol 2003; 181(2): 231-40.

[21] Volpe JJ. Brain injury in premature infants: a complex amalgam of destructive and developmental disturbances. Lancet Neurol 2009; 8(1): 110-24.

[22] Zammit C, Muscat R, Di Giovanni G, Valentino M. Vulnerability of white matter to ischemia varies during development. Malta Med J 2011; 23(3), 45-51

[23] Alix JJ, Zammit C, Riddle A et al. Central axons preparing to myelinate are highly sensitive to ischaemic injury. Ann Neurol 2012; 72(6): 936-51.

[24] Fern R, Möller T. Rapid ischaemic cell death in immature oligodendrocytes: a fatal glutamate release feedback loop. J Neurosci 2000; 20(1): 34-42.

[25] Cherubini E, Ben-Ari Y, Krnjević K. Anoxia produces smaller changes in synaptic transmission, membrane potential, and input resistance in immature rat hippocampus. J Neurophysiol 1989; 62(4): 882-95

[26] Crépel V, Krnjević K, Ben-Ari Y. Developmental and regional differences in the vulnerability of rat hippocampal slices to lack of glucose. Neuroscience 1992; 47(3): 579-87.

[27] Fern R, Davis P, Waxman SG, Ransom BR. Axon conduction and survival in CNS white matter during energy deprivation: a developmental study. J Neurophysiol 1998; 79(1): 95-105.

[28] Foster RE, Connors BW, Waxman SG. Rat optic nerve: electrophysiological, pharmacological and anatomical studies during development. Brain Res 1982; 255(3): 371-86.

[29] Skoff RP, Price DL, Stocks A. Electron microscopic autoradiographic studies of gliogenesis in rat optic nerve. II. Time of origin. J Comp Neurol 1976; 169(3): 313-34.

[30] Wiggins RC. Myelin development and nutritional insufficiency. Brain Res 1982; 257(2): 151-75.

[31] Azzarelli B, Meade P, Muller J. Hypoxic lesions in areas of primary myelination. A distinct pattern in cerebral palsy. Childs Brain 1980; 7(3): 132-45.

[32] Davison AN, Dobbing J. Myelination as a vulnerable period in brain development. Br Med Bull 1966; 22(1): 40-4.

[33] Fowler JH, McCracken E, Dewar D, McCulloch J. Intracerebral injection of AMPA causes axonal damage in vivo. Brain Res 2003; 991(1-2): 104-12.

[34] Waxman SG, Black JA, Kocsis JD, Ritchie JM. Low density of sodium channels supports action potential conduction in axons of neonatal rat optic nerve. Proc Natl Acad Sci USA 1989; 86(4): 1406-10.

[35] Xia Y, Haddad GG. Postnatal development of voltage-sensitive $\mathrm{Na}+$ channels in rat brain. J Comp Neurol 1994; 345(2): 279-87.

[36] Alzheimer C, Schwindt PC, Crill WE. Postnatal development of a persistent $\mathrm{Na}+$ current in pyramidal neurons from rat sensorimotor cortex. J Neurophysiol 1993; 69(1): 290-2.

[37] Alix JJ, Fern R. Glutamate receptor-mediated ischaemic injury of premyelinated central axons. Ann Neurol 2009; 66(5): 682-93.

[38] Kauppinen TM, Swanson RA. The role of poly(ADP-ribose) polymerase-1 in CNS disease. Neuroscience 2007; 145(4): 1267-72

[39] Lehnardt S, Massillon L, Follett P, et al. Activation of innate immunity in the CNS triggers neurodegeneration through a Toll-like receptor 4-dependent pathway. Proc Natl Acad Sci USA 2003; 100(14): 8514-9.

[40] Kim SS, Kong PJ, Kim BS, Sheen DH, Nam SY, Chun W. Inhibitory action of minocycline on lipopolysaccharide-induced release of nitric oxide and prostaglandin E2 in BV2 microglial cells. Arch Pharm Res 2004; 27(3): 314-8.

[41] Pitt D, Nagelmeier IE, Wilson HC, Raine CS. Glutamate uptake by oligodendrocytes: Implications for excitotoxicity in multiple sclerosis. Neurology 2003; 61(8): 1113-20.

[42] Pang Y, Campbell L, Zheng B, Fan L, Cai Z, Rhodes P. Lipopolysaccharide-activated microglia induce death of oligodendrocyte 
progenitor cells and impede their development. Neuroscience 2010; 166(2): 464-75.

[43] Billiards SS, Haynes RL, Folkerth RD, et al. Myelin abnormalities without oligodendrocyte loss in periventricular leukomalacia. Brain Pathol 2008; 18(2): 153-63.

[44] Haynes RL, Folkerth RD, Trachtenberg FL, Volpe JJ, Kinney HC. Nitrosative stress and inducible nitric oxide synthase expression in periventricular leukomalacia. Acta Neuropathol 2009; 118(3): 3919.

[45] Billiards SS, Haynes RL, Folkerth RD, Trachtenberg FL, Liu LG, Volpe JJ, Kinney HC. Development of microglia in the cerebral white matter of the human fetus and infant. J Comp Neurol 2006; 497(2): 199-208.

[46] Deng W. Neurobiology of injury to the developing brain. Nat Rev Neurol 2010; 6(6): 328-36.

[47] Alvarez JI, Katayama T, Prat A. Glial influence on the blood brain barrier. Glia 2013; 61(12): 1939-58.

[48] Halassa MM, Haydon PG. Integrated brain circuits: astrocytic networks modulate neuronal activity and behavior. Annu Rev Physiol 2010; 72: 335-55.

[49] Fern R. Ischemia: astrocytes show their sensitive side. Prog Brain Res 2001; 132: 405-11.

[50] Shannon C, Salter M, Fern R. GFP imaging of live astrocytes: regional differences in the effects of ischaemia upon astrocytes. $\mathrm{J}$ Anat 2007; 210(6): 684-92.

[51] Fern R. Intracellular calcium and cell death during ischemia in neonatal rat white matter astrocytes in situ. J Neurosci 1998; 18(18): 7232-43.

[52] Takahashi JL, Giuliani F, Power C, Imai Y, Yong VW. Interleukin1 beta promotes oligodendrocyte death through glutamate excitotoxicity. Ann Neurol 2003; 53(5): 588-95.

[53] Wender R, Brown AM, Fern R, Swanson RA, Farrell K, Ransom BR. Astrocytic glycogen influences axon function and survival during glucose deprivation in central white matter. J Neurosci 2000; 20(18): 6804-10.

[54] Back SA, Rosenberg PA. Pathophysiology of glia in perinatal white matter injury. Glia 2014; 62(11): 1790-815.

[55] Bax M, Goldstein M, Rosenbaum P, et al. Proposed definition and classification of cerebral palsy. Dev Med Child Neurol 2005; 47(8): 571-6.

[56] Darlow BA, Cust AE, Donoghue DA. Improved outcomes for very low birthweight infants: evidence from New Zealand national population-based data. Arch Dis Child Fetal Neonatal Ed 2003; 88(1): F23-8.

[57] Everts R, Pavlovic J, Kaufmann F, et al. Cognitive functioning, behavior, and quality of life after stroke in childhood. Child Neuropsychol 2008; 14(4): 323-38

[58] Pavlovic J, Kaufmann F, Boltshauser E, et al. Neuropsychological problems after paediatric stroke: two year follow-up of Swiss children. Neuropediatrics 2006; 37(1): 13-9.

[59] Max JE, Bruce M, Keatley E, Delis D. Pediatric stroke: plasticity, vulnerability and age of lesion onset. J Neuropsychiatry Clin Neurosci 2010; 22: 30-39.

[60] Chapman SB, Max JE, Gamino JF, McGlothlin JH, Cliff SN. Discourse plasticity in children after stroke: age at injury and lesion effects. Pediatr Neurol 2003; 29: 34-41.

[61] Allman C, Scott RB. Neuropsychological sequelae following pediatric stroke: a nonlinear model of age at lesion effects. Child Neuropsychol 2013; 19: 97-107.

[62] Westmacott R, Askalan R, MacGregor D, Anderson P, Deveber G. Cognitive outcome following unilateral arterial ischaemic stroke in childhood: effects of age at stroke and lesion location. Dev Med Child Neurol 2010; 52(4): 386-93.

[63] Studer M, Boltshauser E, Capone Mori A, et al. Factors affecting cognitive outcome in early pediatric stroke. Neurology 2014; 82(9): 784-92.

[64] Maitre NL, Marshall DD, Price WA, et al. Neurodevelopmental outcome of infants with unilateral or bilateral periventricular hemorrhagic infarction. Pediatrics 2009; 124(6): e1153-60.

[65] Nosarti C, Al-Asady MH, Frangou S, et al. Adolescents who were born very preterm have decreased brain volumes. Brain 2002; 125(Pt 7): 1616-23..

[66] Isaacs EB, Edmonds CJ, Lucas A, Gadian DG. Calculation difficulties in children of very low birthweight: a neural correlate. Brain 2001; 124(Pt 9): 1701-7.
[67] Inder TE, Warfield SK, Wang H, Huppi PS, Volpe JJ. Abnormal cerebral structure is present at term in premature infants. Pediatrics Feb 2005; 115(2): 286e94.

[68] de Kieviet JF, Zoetebier L, van Elburg RM, Vermeulen RJ, Oosterlaan J. Brain development of very preterm and very lowbirthweight children in childhood and adolescence: a meta-analysis. Dev Med Child Neurol Apr 2012; 54(4): 313e23.

[69] Aarnoudse-Moens CS, Weisglas-Kuperus N, vanGoudoever JB, Oosterlaan J. Meta-analysis of neurobehavioral outcomes in very preterm and/or very low birth weight children. Pediatrics Aug 2009; 124(2): 717e28.

[70] Bjuland KJ, Rimol LM, Løhaugen GC, Skranes J. Brain volumes and cognitive function in very-low-birth-weight (VLBW) young adults. Eur J Paediatr Neurol 2014; 18(5): 578-90.

[71] Taylor HG, Filipek PA, Juranek J, et al. Brain volumes in adolescents with very low birth weight: effects on brain structure and associations with neuropsychological outcomes. Dev Neuropsychol 2011; 36(1): 96-117.

[72] Jakobson LS, Frisk V, Downie AL. Motion-defined form processing in extremely premature children. Neuropsychologia 2006; 44(10): 1777-86.

[73] Pavlova M, Sokolov AN, Krägeloh-Mann I. Arithmetic and brain connectivity: mental calculation in adolescents with periventricular lesions. Neuropsychologia 2009; 47(2): 439-45.

[74] Stoll BJ, Hansen N, Fanaroff AA, et al. Late-onset sepsis in very low birth weight neonates: The experience of the NICHD Neonatal Research Network. Pediatrics 2002; 110(2): 285-91.

[75] Shah DK, Doyle LW, Anderson PJ, et al. Adverse neurodevelopment in preterm infants with postnatal sepsis or necrotizing enterocolitis is mediated by white matter abnormalities on magnetic resonance imaging at term. J Pediatr 2008; 153(2): 170-5.

[76] Graham EM, Holcroft CI, Rai KK, Donohue PK, Allen MC. Neonatal cerebral white matter injury in preterm infants is associated with culture positive infections and only rarely with metabolic acidosis. Am J Obstet Gynecol 2004; 191(4): 1305-10.

[77] Stoll BJ, Hansen NI, Adams-Chapman I, et al. Neurodevelopmental and growth impairment among extremely low-birth-weight infants with neonatal infection. JAMA 2004; 292(19): 2357-65.

[78] Adams-Chapman I, Stoll BJ. Neonatal infection and long-term neurodevelopmental outcome in the preterm infant. Curr Opin Infect Dis 2006; 19(3): 290-7.

[79] van der Ree M, Tanis JC, Van Braeckel KN, Bos AF, Roze E. Functional impairments at school age of preterm born children with late-onset sepsis. Early Hum Dev 2011; 87(12): 821-6.

[80] Glass HC, Bonifacio SL, Chau V, et al. Recurrent postnatal infections are associated with progressive white matter injury in premature infants. Pediatrics 2008; 122(2): 299-305

[81] Andrikopoulou M, Almalki A, Farzin A, Cordeiro CN, Johnston MV, Burd I. Perinatal biomarkers in prematurity: early identification of neurologic injury. Int J Dev Neurosci 2014; 36: 25-31.

[82] Buonocore G, Perrone S, Gioia D, et al. Nucleated red blood cell count at birth as an index of perinatal brain damage. Am J Obstet Gynecol 1999; 181(6): 1500-5.

[83] Goel M, Dwivedi R, Gohiya P, Hegde D. Nucleated red blood cell in cord blood as a marker of perinatal asphyxia. J Clin Neonatol 2013; 2(4): 179-82.

[84] Foerch C, Curdt I, Yan B, et al. Serum glial fibrillary acidic protein as a biomarker for intracerebral haemorrhage in patients with acute stroke. J Neurol Neurosurg Psychiatry 2006; 77(2): 181-4.

[85] Ennen CS, Huisman TA, Savage WJ, et al. Glial fibrillary acidic protein as a biomarker for neonatal hypoxic-ischaemic encephalopathy treated with whole-body cooling. Am J Obstet Gynecol 2011; 205(3): 251.e1-7.

[86] Khwaja O, Volpe JJ. Pathogenesis of cerebral white matter injury of prematurity. Arch Dis Child Fetal Neonatal Ed 2008; 93(2): F153-61.

[87] Ellison VJ, Mocatta TJ, Winterbourn CC, Darlow BA, Volpe JJ, Inder TE. The relationship of CSF and plasma cytokine levels to cerebral white matter injury in the premature newborn. Pediatr Res 2005; 57(2): 282-6.

[88] Ramaswamy V, Horton J, Vandermeer B, Buscemi N, Miller S, Yager J. Systematic review of biomarkers of brain injury in term neonatal encephalopathy. Pediatr Neurol 2009; 40(3): 215-26.

[89] Qian J, Zhou D, Wang YW. Umbilical artery blood S100beta protein: a tool for the early identification of neonatal hypoxicischaemic encephalopathy. Eur J Pediatr 2009; 168(1): 71-7. 
[90] Gazzolo D, Frigiola A, Bashir M, et al. Diagnostic accuracy of S100B urinary testing at birth in full-term asphyxiated newborns to predict neonatal death. PLoS One 2009; 4(2): e4298.

[91] Ledebt A, Savelsbergh GJ, Sie LT, van der Knaap MS. Walking and periventricular leukomalacia: locomotor characteristics and brain imaging (MRI). Infant Behav Dev 2008; 31(4): 655-64.

[92] Inder TE, Anderson NJ, Spencer C, Wells S, Volpe JJ. White matter injury in the premature infant: a comparison between serial cranial sonographic and MR findings at term. AJNR Am J Neuroradiol 2003; 24(5): 805-9.

[93] Vohr BR, Wright LL, Poole WK, McDonald SA. Neurodevelopmental outcomes of extremely low birth weight infants $<32$ weeks' gestation between 1993 and 1998. Pediatrics 2005; 116(3): 635-43.

[94] Hintz SR, Kendrick DE, Vohr BR, et al. Changes in neurodevelopmental outcomes at 18 to 22 months' corrected age among infants of less than 25 weeks' gestational age born in 1993-1999. Pediatrics 2005; 115(6): 1645-51.

[95] Ancel PY, Livinec F, Larroque B, et al. Cerebral palsy among very preterm children in relation to gestational age and neonatal ultrasound abnormalities: the EPIPAGE cohort study. Pediatrics 2006; 117(3): 828-35.

[96] Fritz J, Polansky SM, O'Connor SC. Neonatal Neurosonography. Semin Ultrasound CT MR 2014; 35(4): 349-364.

[97] Kuban KC, Allred EN, O'Shea TM, et al. Cranial ultrasound lesions in the NICU predict cerebral palsy at age 2 years in children born at extremely low gestational age. J Child Neurol 2009; 24(1): 63-72.

[98] Adcock LM, Moore PJ, Schlesinger AE, Armstrong DL. Correlation of ultrasound with postmortem neuropathologic studies in neonates. Pediatr Neurol 1998; 19(4): 263-71.

[99] Inder TE, Wells SJ, Mogridge NB, Spencer C, Volpe JJ. Defining the nature of the cerebral abnormalities in the premature infant: a qualitative magnetic resonance imaging study. J Pediatr 2003b; 143(2): 171-9.

[100] van Wezel-Meijler G, De Bruïne FT, Steggerda SJ, et al.. Ultrasound detection of white matter injury in very preterm neonates: practical implications. Dev Med Child Neurol 2011; 53 Suppl 4: 29-34.

[101] Mirmiran M, Barnes PD, Keller K, et al. Neonatal brain magnetic resonance imaging before discharge is better than serial cranial ultrasound in predicting cerebral palsy in very low birth weight preterm infants. Pediatrics 2004; 114(4): 992-8.

[102] Woodward LJ, Anderson PJ, Austin NC, Howard K, Inder TE. Neonatal MRI to predict neurodevelopmental outcomes in preterm infants. N Engl J Med 2006; 355(7): 685-94.

[103] Imamura T, Ariga H, Kaneko M, et al. Neurodevelopmental outcomes of children with periventricular leukomalacia. bPediatr Neonatol 2013; 54(6): 367-72.

[104] Kuzmanić-Samija R, Resić B, Tomasović M, et al. West syndrome with periventricular leukomalacia: ten-year clinical study. Coll Antropol 2008; 32 Suppl 1: 105-11.

[105] Oishi K, Faria AV, Yoshida S, Chang L, Mori S. Reprint of "Quantitative evaluation of brain development using anatomical MRI and diffusion tensor imaging". Int J Dev Neurosci 2014; 32: 28-40.

[106] Wang S, Fan G, Xu K, Wang C. Potential of diffusion tensor MR imaging in the assessment of cognitive impairments in children with periventricular leukomalacia born preterm. Eur J Radiol 2013; 82(1): 158-64.

[107] Deary IJ, Bastin ME, Pattie A, et al. White matter integrity and cognition in childhood and old age. Neurology 2006; 66(4): 50512.
[108] Schmithorst VJ, Wilke M, Dardzinski BJ, Holland SK. Cognitive functions correlate with white matter architecture in a normal pediatric population: a diffusion tensor MRI study. Hum Brain Mapp 2005; 26(2): 139-47.

[109] Azzopardi DV, Strohm B, Edwards AD, et al. Moderate hypothermia to treat perinatal asphyxial encephalopathy. N Engl J Med 2009; 361(14): 1349-58.

[110] Edwards AD1, Brocklehurst P, Gunn AJ, et al. Neurological outcomes at 18 months of age after moderate hypothermia for perinatal hypoxic ischaemic encephalopathy: synthesis and meta-analysis of trial data. BMJ 2010; 340: c363.

[111] Iwata O, Iwata S. Filling the evidence gap: how can we improve the outcome of neonatal encephalopathy in the next 10 years? Brain Dev 2011; 33(3): 221-8.

[112] Ichiba H, Tamai H, Negishi H, et al. Randomized controlled trial of magnesium sulfate infusion for severe birth asphyxia. Pediatr Int 2002; 44(5): 505-9.

[113] Rouse DJ, Hirtz DG, Thom E, et al. A randomized, controlled trial of magnesium sulfate for the prevention of cerebral palsy. $\mathrm{N}$ Engl J Med 2008; 359(9): 895-905.

[114] Liu C, Lin N, Wu B, Qiu Y. Neuroprotective effect of memantine combined with topiramate in hypoxic-ischaemic brain injury. Brain Res 2009; 1282: 173-82.

[115] Filippi L, Poggi C, la Marca G, et al. Oral topiramate in neonates with hypoxic ischaemic encephalopathy treated with hypothermia: a safety study. J Pediatr 2010; 157(3): 361-6.

[116] Zhu C, Kang W, Xu F, et al. Erythropoietin improved neurologic outcomes in newborns with hypoxic-ischaemic encephalopathy. Pediatrics 2009; 124(2): e218-26.

[117] Kaandorp JJ, Benders MJ, Rademaker CM, et al. Antenatal allopurinol for reduction of birth asphyxia induced brain damage (ALLO-Trial); a randomized double blind placebo controlled multicenter study.BMC Pregnancy Childbirth 2010; 10: 8 .

[118] Fan X, van Bel F. Pharmacological neuroprotection after perinatal asphyxia. J Matern Fetal Neonatal Med 2010; 23 Suppl 3: 17-9.

[119] Jatana M, Singh I, Singh AK, Jenkins D. Combination of systemic hypothermia and $\mathrm{N}$-acetylcysteine attenuates hypoxic-ischaemic brain injury in neonatal rats. Pediatr Res 2006; 59(5): 684-9.

[120] Jianrong Li, Hong Wang, and Paul A. Rosenberg. Vitamin K Prevents Oxidative Cell Death by Inhibiting Activation of 12 Lipoxygenase in Developing Oligodendrocytes. J Neurosci Res 2009; 87(9): 1997-2005.

[121] Girard S, Sébire H, Brochu ME, Briota S, Sarret P, Sébire G. Postnatal administration of IL-1Ra exerts neuroprotective effects following perinatal inflammation and/or hypoxic-ischemic injuries. Brain Behav Immun 2012; 26(8): 1331-9.

[122] Pimentel-Coelho PM, Magalhães ES, Lopes LM, deAzevedo LC, Santiago MF, Mendez-Otero R. Human cord blood transplantation in a neonatal rat model of hypoxic-ischaemic brain damage: functional outcome related to neuroprotection in the striatum. Stem Cells Dev 2010; 19(3): 351-8.

[123] Pimentel-Coelho PM, Mendez-Otero R. Cell therapy for neonatal hypoxic-ischaemic encephalopathy. Stem Cells Dev 2010; 19(3): 299-310.

[124] Donega V, Nijboer CH, van Tilborg G, Dijkhuizen RM, Kavelaars A, Heijnen CJ. Intranasally administered mesenchymal stem cells promote a regenerative niche for repair of neonatal ischaemic brain injury. Exp Neurol 2014; 261C: 53-64.

[125] Mancías-Guerra C, Marroquín-Escamilla AR, González-Llano O et al. Safety and tolerability of intrathecal delivery of autologous bone marrow nucleated cells in children with cerebral palsy: an open-label phase I trial. Cytotherapy 2014; 16(6): 810-20. 